\title{
Curriculum Studies in Health and Physical Education
}

\section{Implementing the teaching personal and social responsibility model within preschool education: strengths, challenges and strategies}

\author{
Inês Pavão, Fernando Santos, Paul M. Wright \& Francisco Gonçalves
}

To cite this article: Inês Pavão, Fernando Santos, Paul M. Wright \& Francisco Gonçalves (2018): Implementing the teaching personal and social responsibility model within preschool education: strengths, challenges and strategies, Curriculum Studies in Health and Physical Education, DOI: 10.1080/25742981.2018.1552499

To link to this article: https://doi.org/10.1080/25742981.2018.1552499

\section{曲 Published online: 07 Dec 2018.}

\section{Submit your article to this journal $\sqsubset$}

Џll Article views: 12

View Crossmark data ¿ 


\title{
Implementing the teaching personal and social responsibility model within preschool education: strengths, challenges and strategies
}

\author{
Inês Pavão ${ }^{a}$, Fernando Santos ${ }^{a, b}$, Paul M. Wright ${ }^{c}$ and Francisco Gonçalves ${ }^{a}$ \\ ${ }^{a}$ School of Higher Education, Polytechnic Institute of Viana do Castelo, Viana do Castelo, Portugal; ${ }^{\text {binED }}$ \\ Centre for Research and Innovation in Education, School of Higher Education, Polytechnic Institute of Porto, \\ Porto, Portugal; 'Department of Kinesiology and Physical Education, Northern Illinois University, DeKalb, IL, \\ USA
}

\begin{abstract}
The teaching personal and social responsibility (TPSR) model has been considered a valuable tool for children to reach their full potential in life. However, little research has been conducted with the TPSR model in preschool contexts. The purpose of the present study was to understand the experiences of a program leader while implementing a TPSR-based program within a preschool setting. The participants were 24 children with 5 years of age attending a school located in the north of Portugal, and the program leader. Data sources included reflexive journaling, field notes and participant observations. Findings suggest the TPSR model could be adapted and implemented with preschool children. However, there is a need to consider specific adaptations to develop TPSR-based interventions and facilitate responsibility outcomes. This study provided a novel understanding of how TPSR may be implemented in a preschool context to foster social and emotional learning and enhance school readiness.
\end{abstract}

\section{KEYWORDS}

Life skills; physical education; reflection; action-research

Physical education plays an important role in providing opportunities for children to adopt a healthy lifestyle, develop motor skills and also attain personal and social skills needed to reach their full potential in life (Hellison, 2011; Pica, 2006; Sanders, 2002). Scholars (Martinek \& Hellison, 2009; Wright \& Li, 2009) have attempted to understand how physical education-based programs may generate these outcomes and provide meaningful developmental experiences for children and youth in general. Participation in programs based on a positive youth development (PYD) perspective has been linked to positive developmental outcomes such as increases in self-control, goal setting and leadership skills (Fraser-Thomas, Côté, \& Deakin, 2005). PYD should be viewed as an asset-based approach to youth development that aims to foster personal and social skills considered key for children to flourish across the developmental spectrum (Damon, 2004; Lerner et al., 2014). PYD-based programs are structured to intentionally provide opportunities for personal and social skills development which has proven to be 
an effective approach (Holt et al., 2017). Additionally, recent research (Holt et al., 2017; Pierce, Gould, \& Camiré, 2017) has shown how intentionally structured environments may produce more PYD outcomes. The current study has been undertaken to explore the potential of adapting a well-established PYD instructional model in preschool physical education.

Whether connected to sport, physical education, or other settings, PYD outcomes are often equated with social and emotional learning competencies such as self-awareness, self-management, social awareness, relationship skills and responsible decision-making (Jacobs \& Wright, 2014). Such skills and competencies are relevant and necessary at all stages of development and especially during major life transitions (Erikson, 1968). For example, the concept of school readiness for preschoolers means that they need to be prepared not only in terms of language, cognitive, and literacy development, but also in terms of their physical and social-emotional development (Heroman, Burts, Berke, \& Bickart, 2010). Leading researchers (Durlak, Weissberg, Dymnicki, Taylor, \& Schellinger, 2011) consider it paramount to foster social and emotional learning through effective evidence-based programs that target these types of outcomes. Nevertheless, the same authors highlighted that, in some cases, 'Schools may not be aware of effective programs, fail to choose them from among alternatives, do not implement the interventions correctly, or do not continue programs even if they are successful during a pilot or demonstration period' (Durlak et al., 2011, p. 420). In order to overcome these challenges, several models have been developed to guide schools and further enhance preschool children's developmental experiences (Moreno, Nagasawa, \& Schwartz, 2018). Therefore, programs with a holistic focus should be an integral part of the preschool experience (Pica, 2006; Sanders, 2002). Most of these models do not address physical education directly, but provide broad pedagogical guidelines that have been useful within a vast array of educational settings such as preschool education (Dusenbury, Zadrazil, Mart, \& Weissberg, 2011). Hence, models such as the teaching personal and social responsibility (TPSR) may shed light on how to generate social and emotional learning outcomes through physical education. As such, Hellison (2011) and other scholars (Jacobs \& Wright, 2014; Severinsen, 2014) have highlighted the role played by physical education in fostering these outcomes and suggested the need to implement this model in childhood.

\section{TPSR through physical education}

Within the PYD literature, several models have emerged to guide physical education teachers and sport educators and help them facilitate PYD outcomes (Danish \& Nellen, 1997; Hellison, 2011). As mentioned previously, one of these is the TPSR model designed by Hellison (2011) that aims to teach personal and social responsibility through a set of responsibility levels: level I, respect for others; level II, self-motivation; level III, self-direction; level IV, caring; level V, transference to other life domains (see Table 1 for a description of each responsibility level).

The TPSR model provides specific strategies, objectives and concrete behaviours for teachers to focus on, but it is not meant to be a scripted or delivered in a rigid way (Hellison, 2011). In fact, it should be viewed as a creative process managed by each teacher and developed to fulfil students' needs while balancing contextual considerations with the 
Table 1. Levels of responsibility adapted from Escartí et al. (2012).

\begin{tabular}{|c|c|}
\hline Responsibility levels & Goals \\
\hline $\begin{array}{l}\text { (1) Respect the rights and feelings } \\
\text { of others }\end{array}$ & $\begin{array}{l}\text { Resolve conflicts through dialogue; accept and include all peers in the activities; listen } \\
\text { to the teacher and classmates when they are speaking; speak without interrupting } \\
\text { others; avoid insulting others or calling them names }\end{array}$ \\
\hline (2) Effort & $\begin{array}{l}\text { Participate in planned activities even when they are not your favorite; persist in all } \\
\text { activities even if they are difficult; follow the rules of the class such as wearing the } \\
\text { appropriate clothing and adhering to rules and procedures }\end{array}$ \\
\hline (3) Self-direction & $\begin{array}{l}\text { Set short and long-term goals; reflect on and evaluate your own progress honestly; } \\
\text { assume responsibility for tasks; take on leadership roles; participate in activities } \\
\text { whether the teacher is watching or not }\end{array}$ \\
\hline (4) Helping others & Care for others; pay attention to the needs of your classmates \\
\hline (5) Transfer & $\begin{array}{l}\text { Apply what is learned in the 'gym' to other contexts such as the family, the } \\
\text { playground, or your neighbourhood }\end{array}$ \\
\hline
\end{tabular}

guiding principles of TPSR (Martinek \& Hellison, 2009). In order to facilitate these types of outcomes, Hellison (2011) has proposed a TPSR lesson format which is comprised of an awareness talk, group meeting, reflection time, and physical activity.

In recent decades, researchers have conducted several studies to assess the implementation process of the TPSR model in various settings. Consistently, studies indicate the TPSR model may foster responsibility outcomes such as leadership development, emotional control and perseverance (Pozo, Grao-Cruces, \& Pérez-Ordás, 2016). For instance, this model has been used successfully in several countries such as South Korea (Jung \& Wright, 2012) and Canada (Barker \& Forneris, 2012). Jung and Wright (2012) conducted a multiple case study to analyse the cultural translation of the TPSR model within a South Korean middle school. The participants were six students who were all 14 years old. Findings suggested that students were able to attain the TPSR goals of effort and caring as self-direction represented a challenge due to the cultural differences, specifically the way autonomy was viewed in South Korea. Barker and Forneris (2012) presented a set of reflections and suggestions about TPSR implementation based on previous findings of the PULSE program that targeted Canadian underserved youth. These authors highlighted the need to further develop community-based programs and through the TPSR model increase the quality of such interventions. These programs have supported the notion that TPSR interventions may generate positive outcomes within adolescent youth. Additionally, many TSPR-based programs have been delivered in afterschool projects, high school sport and coaching clubs with adolescent youth (Jung \& Wright, 2012; Walsh, Ozaeta, \& Wright, 2010). Few studies have been conducted with children, more specifically with preschool children who are at a sensitive stage of their developmental process and require guidance to attain social and emotional learning outcomes (Lee, 2009; Liu, Karp, \& Davis, 2010). Therefore, a need exists in the TPSR literature to design, implement and evaluate programs for preschool age children.

\section{TPSR to preschool children}

There are several underlying pedagogical principles that are at the core of the TPSR model and aligned with the developmental needs presented by young children (Liu et al., 2010; Wright \& Stork, 2013). In fact, the pedagogical guidelines included in preschool education emphasise the need to intentionally design physical education experiences and implement 
concrete strategies that help children learn a sense of self, foster positive relationships with others and become active learners (Wright \& Stork, 2013). Social and emotional learning competencies have been considered key at this developmental stage as many scholars (Hellison, 2011; Holt, 2016; Liu et al., 2010; Wright \& Stork, 2013) have shown that an intentionally designed environment may increase positive developmental outcomes (e.g. academic performance, positive social interactions).

The themes that characterise the TPSR model (Hellison, 2011) align with preschool children's developmental needs and the pedagogical guidelines recommended for this developmental stage. First, the teacher-student relationship is considered to have a critical role as children should be valued, supported and treated with respect. The quality of the teacher-student relationship in early childhood is considered critical to facilitating a positive climate and predicting positive developmental outcomes (Hamre \& Pianta, 2005; Mashburn et al., 2008). Second, physical education is viewed as a platform for teaching life skills and values such as responsibility are embedded in the general program. Preschool education has been acknowledged as a critical stage for personal and social responsibility development (Erikson, 1968). Several scholars (Hellison, 2011; Liu et al., 2010; Wright, White, \& Gaebler-Spira, 2004) have mentioned the need to intentionally engage children in meaningful activities adjusted to their cognitive, social and emotional development that may help them attain personal and social responsibility outcomes. Finally, the TPSR model is based on an empowerment framework that provides students with choices and voices. Within preschool education, some studies (Webster-Stratton, Reid, \& Hammond, 2004) have shown that an autonomybased climate that includes features inherent to the TPSR model may lead to more competent social interactions and help children became more emotionally mature once they reach primary school. More specifically, one of the core premises of the TPSR model is providing support for children to become gradually more responsible for their behaviours and for others by creating an autonomy-based climate in which voices and choices are paramount. This pedagogical principle has been supported by previous research with preschool children that have found that an autonomy-based climate may lead to positive outcomes such as better relational skills and emotional regulation (Dusenbury et al., 2011).

Researchers who focus on the developmental experiences of preschool children highlight the crucial role played by positive adult-child relationships, physical education and empowerment (Dusenbury et al., 2011). These features of successful preschool programs align strongly with developmental TPSR interventions (Wright et al., 2004). Walsh's (2008, p. 2010) intervention work with elementary-aged children suggests the need to foster social and emotional learning outcomes and implement the Hellison's (2011) model at an early stage of children's developmental process. These studies have provided valuable insight on well-implemented TPSR programs. Nevertheless, Walsh (2008) recognised the complex nature of working with children and the multiple outcomes that need to be attained in such TPSR programs:

Coaching children, together with a direct reflection component, precluded participants' lofty dreams and romantic accomplishments by reminding them of the hard work, determination, and commitment involved. Career Club was designed to anchor them in the reality of their effort, personality, attitude, patience, and intelligence, combined with persistence and an understanding of the practical choices they would .... (p. 219) 


\section{Teacher training and curriculum development with TPSR}

Quality TPSR programs are influenced by teachers' ability to incorporate a sound TPSR philosophy and coherent practices (Holt, 2016). TPSR-based programs could consider integrating teacher training to help adult leaders develop the necessary skill set to provide developmentally sound experiences and increase model fidelity. For example, previous studies have utilised the Tool for Assessing Responsibility-based Education (TARE) to analyse the influence of TPSR-focused teacher training on teachers' ability to implement this model, and to help them integrate TPSR strategies (Wright \& Craig, 2011; Hemphill, Templin, \& Wright, 2015). Several studies have analysed the effectiveness of the TPSR model (Hemphill et al., 2015) and conducted process evaluations (Barker \& Forneris, 2012), however, few have focused on developing and describing TPSR teacher training programs which provide contextual insight on the effects of a particular intervention (Escartí et al., 2012; Hemphill et al., 2015). The expansion of the TPSR model to a variety of contexts such as afterschool projects and programs for children with special needs (Barker \& Forneris, 2012; Wright et al., 2004) requires a more detailed analysis of teachers' behaviours while fostering responsibility and also a more comprehensive understanding of how teacher training guidelines are used in specific contexts to produce responsibility outcomes which may influence future research and practice. These elements are critical as research on the TPSR model advances to unexplored settings such as preschool education. There is also a need to develop appropriate teacher training programs that promote the key pedagogical principles behind the TPSR model and simultaneously engage preschool teachers in developing strategies and adaptations to fit their students and their particular context. Such adaptations should be guided by preschool children's cognitive, social, physical, and emotional skills (i.e. activities for each responsibility level should be designed accordingly) and rooted in the need to intentionally develop personal and social responsibility through a set developmentally appropriate responsibility-based strategies that could be embedded in physical education.

Previous research has been mainly focused on adolescent students' perceptions and teachers' responsibility behaviours (Escartí et al., 2012; Ward, Parker, Henschel-Pellett, \& Perez, 2012). For example, Escartí et al. (2012) conducted a study with adolescents at risk of social exclusion and attempted to understand how the TPSR model could foster responsibility outcomes. Findings showed this model was effective and these researchers suggested the need to start at younger ages to attain more responsibility outcomes. However, research that has focused on the processes related to the implementation of the TPSR model is somewhat scarce (Jung \& Wright, 2012; Lee, 2009). Additionally, research conducted with the TPSR model and preschool children is still in its infancy. This research avenue may provide new understanding related to implementing the TPSR model with preschool children and helping teachers to face challenges experienced in this context as they try to foster responsibility outcomes.

Action-research designs have been widely used with physical education teachers and enable a process and product evaluation centred on several action-research cycles (Casey, 2013). In the present study, each action-research cycle involved the processes that lead to developing a level of responsibility, specifically focused on the challenges and emerging issues associated to the program leader's intervention. A new cycle was created through reflection and once the research team deemed appropriate to move to 
the next level of responsibility as a new set of challenges were identified (Casey, 2013). Therefore, this action-research study aimed to understand the experiences of a program leader who is new to the TPSR model while implementing a TPSR-based program within a preschool setting.

\section{Methods}

\section{Participants}

The participants in this study were 24 children with 5 years of age (13 males and 11 females) who had not been involved in any TPSR-based program prior to this research study. The participants had few physical education experiences as they had occasionally a maximum of one 30-minute physical education session per week. Additionally, the participants in the program were attending a school located in a rural area at northern Portugal. Four of the children came from families living in poverty and were of gypsy descent (i.e. ethnic group). The other children came from middle-class families. The first author, who was responsible for implementing the TPSR-based program, attended a master's course in Education at a local Polytechnic Institute where she was first exposed to the TPSR model and received teacher training by the second author on how to develop and implement the model. The second author has a $\mathrm{PhD}$ in sport sciences, is an assistant professor at a local polytechnic institute and has been conducting research with the TPSR model for several years. Additionally, the second author is a former physical teacher who has implemented the TPSR model within school-based projects. At the time of this study, the program leader was conducting the last practicum before finishing the master's course. At the time of the study, she had a bachelor's degree in Education and had worked previously with this group of children for a three-month period (i.e. during another practicum).

\section{TPSR-focused teacher education}

Prior to implementing the TPSR-based program, the first author participated in an eighthour TPSR-focused course delivered by the second author who had been implementing the TPSR model for five years within school-based projects. The course involved an initial four-hour session focused on: (a) a PYD conceptualisation; (b) TPSR main pedagogical principles and foundations; (c) TPSR-based objectives, responsibility levels, strategies and activities; (d) reflexive tools to improve the quality of the implementation and model fidelity (Hellison, 2011). Two other sessions (i.e. two hours each) were conducted to provide guidance on how to implement the TPSR model.

Throughout the three-month period in which the program was delivered, regular meetings (i.e. once a week) took place between the program leader and the second author in order to discuss emergent challenges and strategies related to each action-research cycle (i.e. each cycle was focused on one level of responsibility), and assure model fidelity. To ensure and assess fidelity, the second author observed two sessions of the program and used direct observations focused on the core principles of the TPSR model (e.g. responsibility-based strategies, core themes and participants' outcomes) to assure program's fidelity and provide insight on how challenges within TPSR could be addressed by the 
program leader. Field notes were taken by the first author based on the components of the TARE (Wright \& Craig, 2011) which is an observational system that has been commonly used to assess responsibility-based interventions and model fidelity. The aforementioned components included empowerment based teaching strategies such as assigning leadership roles, alignment with TPSR themes like integrating responsibility in activities and student behaviour. These field notes were used to guide the discussions between the program leader and the second author and increase model fidelity. In addition, all lessons plans were reviewed by the second author (see Table 2 for the structure of each session and sample activities). In the case of divergent perspectives, the first author's perspective prevailed due to her contextual knowledge.

\section{The TPSR program}

The TPSR-based program was designated 'Early Start To Approaching Responsibility ESTAR' and was conducted between October 2016 and January 2017. Prior to conducting this research, consent forms were delivered to parents and/or legal guardians as they accepted to take part in the study. Physical education sessions occurred twice a week (i.e. in total 20 sessions) and lasted approximately 40 minutes. The program followed Hellison's (2011) guidelines regarding the structure of each session and included an inclass awareness talk, group meeting, reflection time, and physical activity.

However, adaptations were made to integrate the TPSR model within preschool education. In the awareness talk, several examples of desired behaviours (e.g. 'today we will try to listen to each other', 'today let's try to become friends with someone we usually do not speak with or do not know very well') were provided to facilitate comprehension of TPSR objectives. Additionally, an illustrated pyramid was used to identify each level of responsibility and facilitate children's understanding of model goals (e.g. the program

Table 2. Lesson format and sample activities.

\begin{tabular}{|c|c|c|}
\hline Component & Objective & Examples \\
\hline $\begin{array}{l}\text { Awareness } \\
\text { talk }\end{array}$ & $\begin{array}{l}\text { Share the responsibility objectives for the } \\
\text { physical education session }\end{array}$ & $\begin{array}{l}\text { The program leader explained the activity and } \\
\text { focused on behaviours related to respect, } \\
\text { participation/effort and self-direction, specifically on } \\
\text { the need to accept different ideas/opinions, learn to } \\
\text { make decisions and try hard }\end{array}$ \\
\hline $\begin{array}{l}\text { Physical } \\
\text { activity }\end{array}$ & $\begin{array}{l}\text { Embed the levels of responsibility within the } \\
\text { motor skills developed in the physical } \\
\text { education session }\end{array}$ & $\begin{array}{l}\text { Children were divided into small groups and had to } \\
\text { create a game with the materials provided by the } \\
\text { program leader (i.e. balls, ropes, arrows). The } \\
\text { program leader leads the discussion but enabled } \\
\text { the children to discuss their opinions and make } \\
\text { choices. The children had a chance to develop } \\
\text { motor skills such as jumping, throwing and kicking } \\
\text { and gave a name to their game }\end{array}$ \\
\hline $\begin{array}{l}\text { Group } \\
\text { meetings }\end{array}$ & $\begin{array}{l}\text { Discuss positive/negative outcomes of their } \\
\text { involvement in the task and guide children } \\
\text { through the activity }\end{array}$ & $\begin{array}{l}\text { The program leader promoted discussions with each } \\
\text { group to help the children respect others, try hard } \\
\text { and make choices. For example, the program leader } \\
\text { helped groups who were not able to reach an } \\
\text { agreement regarding the rules and name for their } \\
\text { game }\end{array}$ \\
\hline $\begin{array}{l}\text { Reflection } \\
\text { time }\end{array}$ & $\begin{array}{l}\text { Determine how responsibility objectives were } \\
\text { attained in the session }\end{array}$ & $\begin{array}{l}\text { A discussion was promoted to understand how } \\
\text { children were able to attain responsibility } \\
\text { objectives. Each group stood in front of class and } \\
\text { presented their game }\end{array}$ \\
\hline
\end{tabular}


leader highlighted that respect was connected to class rules, effort was associated with trying hard) as photographs of all the students were permanently placed in the classroom. Concerning others adaptations made to typical TPSR programs, the program leader while developing self-direction attempted to provide clear expectations about this level of responsibility and let children choose a game to play (e.g. define a set of rules and a name for the game) in small groups to foster decision-making. In the next PE sessions, children were able to vote on the games they most liked and play them. One of these games included working in small groups to create letters with their bodies. At the beginning and at the end of each session (i.e. in the reflection time) children or the teacher could place their photos in a certain level of responsibility. Within this scheme, a rating system was also used to evaluate children's responsibility behaviours in each physical education session and reflect their accomplishments (e.g. the program leader would award points throughout the activities and later reflect with children). In group meetings and during 'reflection time', children were also challenged to assess their own responsibility behaviours. On a weekly basis, children would receive medals based on the score they had that week. Additionally, a specific space in the classroom was created (i.e. designated the 'peace bench') to use individual conversations and help children overcome difficulties in respecting the rights and feelings of others and regulating emotions (see Figure 1 for representations of these examples).

Several responsibility-based strategies aligned with Hellison's (2011) work with the TPSR model were used such as providing opportunities for decision-making and assigning leaders. For example, children had the chance to choose activities, engage in group discussions about responsibility objectives, stand in front of class to voice their opinion, help others in small groups, and become line leaders. These adaptations focused on the core principles of the TPSR model, but were considerably different from typical TPSR-based programs.

Each action-research cycle focused on identifying emergent challenges, understanding possible strategies to overcome challenges based on the TPSR literature and contextual knowledge, and implementing responsibility-based strategies (Casey, 2013). The first
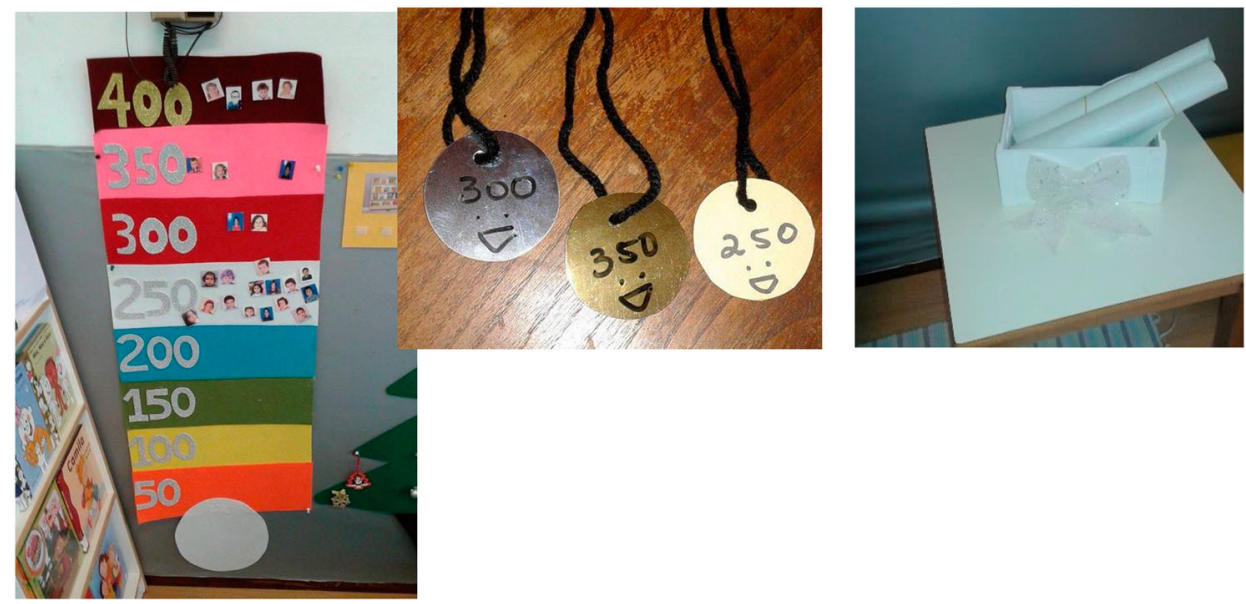

Figure 1. Resources used to represent Hellison's levels of responsibility. 
action-research cycle begun when the program leader observed the program that was being implemented and, in collaboration with the second author, identified the emergent challenges for the upcoming intervention. Each action-research cycle emerged according to children's developmental needs and focused on the program leader's ability to adjust objectives, strategies and activities.

\section{Data collection}

\section{Participant observations and reflexive journaling}

Prior to the TPSR intervention, the first author and program leader sought to understand the program that was being implemented, the preschool teacher's approach towards personal and social responsibility development, and children's TPSR outcomes. First, the program leader collected data to understand the activities, objectives and strategies used by the preschool teacher and children's TPSR outcomes. The initial focus of these participant observations and field notes was to describe the program. Second, the program leader attempted to identify possible activities, objectives and strategies that aligned with the TPSR model and that could contribute to children's developmental needs. This process lasted for a two-week period (i.e. a total of six sessions were observed). Hence, the first author used the observations to (a) familiarise herself with the context and (b) prepare the intervention (Sparkes \& Smith, 2016). Field notes were taken by the program leader and included reflections about each session. These notes were shared with the second author on a weekly basis that posed additional questions, and suggested a more indepth explanation of certain TPSR components (e.g. the first author was advised to provide more detail in explaining the strategies the preschool teacher used to foster respect for others). The second author also added written comments that represented his personal reactions, thoughts, and interpretations.

Member-checking technique was used throughout the data collection and data analysis processes to assure model fidelity (Denzin \& Lincoln, 2011). All the data and didactic material generated (e.g. lesson plans, notes) was included in a reflexive journal (Sparkes $\&$ Smith, 2016). The reflexive journal was used to enable reflection and provided a more comprehensive understanding of each action-research cycle as the first author included all the reflections that derived from the intervention (Denzin \& Lincoln, 2011). As stated previously, this reflexive journal was also used by the second author who included additional edits based on the findings from his observations and interactions with the program leader throughout the present study. In other words, the second author wrote comments reflecting his thoughts and reactions after reading the program leader's notes.

Certain sessions were audio and/or video recorded in order to facilitate reflection as teacher-student interactions' were captured and later the most salient behaviours transcribed as this was a complimentary data source. The aim was to access students' voices as these interactions were included in the reflexive journal. The first author was able to record parts of the sessions that represented crucial TPSR behaviours and later revisited this data to facilitate reflection including a process of re-memory. In addition, recordings were only conducted in few occasions due to the logistical issues behind recording sessions in a preschool setting such as children's distraction due to the presence of a camera and/or feasibility of placing a camera in the gym. 


\section{Data analysis}

All the material was read multiple times to allow the first author to become familiar with the data. These files were shared with the second author who also analysed the material. At this stage, several initial considerations about the data and possible coding procedures were identified and discussed. Then, following the guidelines provided by Sparkes and Smith (2016) a thematic analysis was conducted. An open coding procedure was used to categorise the data as in the later stages of the analysis efforts were made with the objective of finding patterns, creating and merging themes. Themes (e.g. need for the TPSR model) and subthemes (e.g. children's responsibility behaviours) were organised to reflect a particular conceptual hierarchy (Sparkes \& Smith, 2016) and the focus of an action-research cycle. In other words, a theme and/or subtheme emerged once it was deemed representative of the program leader's experiences within a specific actionresearch cycle. This process led to theme alignment and reduction, and helped the research team determine what constituted a theme and subtheme (see Table 3 for themes and subthemes). These themes were reviewed by the research team and deemed representative of the data set. Researchers tried to link the descriptions in the reflexive journal made by the first and second authors with students' lived experiences through the transcriptions of the audio and video recordings. An inductive analysis (Fereday \& Muir-Cochrane, 2006) was conducted in this study representing a data-driven approach as themes emerged based on the contextual nature of each action-research cycle.

Based on a relativist approach (Smith \& McGannon, 2017), several procedures were undertaken to increase the quality of the research (Sparkes \& Smith, 2016). All the quotes included in the results section were translated from Portuguese to the English language by a certified bilingual person. Throughout the analysis, positive and negative outcomes that derived from the program were equally highlighted (i.e. non predominant outcomes were reported). The co-authors served as 'critical friends' (Sparkes \& Smith, 2016), helped with the analysis and writing of this manuscript, and provided constant critique and alternative explanations regarding the decisions made (e.g. the research team lead the first and second author to reflect on how to create an extrinsically motivated climate would align with Hellison's principles and a preschool setting). All the phases of the process were described in detail, as well as the decisions made throughout the intervention to attain transparency (e.g. all the adaptations made in the intervention were reported, details were provided about the objectives and activities chosen and implemented).

\section{Results}

The data analysis process generated three themes. One of these themes was the Need for the TPSR model that reflected the program leader's thoughts on children's responsibility

Table 3. Themes and subthemes.

\begin{tabular}{ll}
\hline Themes & \multicolumn{1}{c}{ Subthemes } \\
\hline Need for the TPSR model & Children's responsibility behaviours \\
Intervention & Recommended practices \\
& Respect for the rights and feelings of others \\
& Participation and effort, and self-direction \\
& Caring \\
Future Recommendations & Need for a long-term TPSR intervention \\
\hline
\end{tabular}


behaviours and possible responsibility-based objectives and strategies that should included in a TPSR intervention. This theme generated two subthemes: (a) children's responsibility behaviours; and (b) recommended practices. The second theme Intervention focused on the challenges faced, and strategies and outcomes generated while implementing the TPSR model, and included three subthemes: (a) respect for the rights and feelings of others; (b) participation and effort, self-direction; (c) caring. The third and final theme was Future Recommendations that included the program leader's thoughts on future TPSR intervention in preschool education, and included one subtheme: (a) need for a long-term TPSR intervention.

\section{Need for the TPSR model}

\section{Children's responsibility behaviours}

This subtheme includes the program leader's reflections on children's responsibility behaviours and developmental needs. Throughout the observation period, it became clear that children struggled with respecting the rights and feelings of others:

Most conflicts and problems emerge within non-structured activities (...) one of the children was playing with the tool box and [two] children took some tools from her (...) she started screaming and almost crying because her colleagues wanted to play with what she had

and 'Another conflict (...) two boys were sitting next to each other and were hitting each other (...) both started screaming and I saw them slapping each other and intervened' (Reflexive journal, October). Some negative behaviours also emerged while children were heading to the gym for a physical education session and other places within the school as the program leader struggled in these transitions:

When we are creating a «train» to leave class (...) children immediately run to the line ... I tried to understand why he [one of the children] was hitting his classmate. I tried to explain that we were all going to the canteen either if we were first or last in line. This child told me that he would not push his classmate anymore. (Reflexive journal, October)

As the program leader became familiar with the TPSR model, children's responsibility behaviours reflected a set of specific skills that needed to be taught:

Based on children's negative behaviors, it is clear the need to implement an intervention program in which responsibility-based strategies need to be used (...) the teaching personal and social responsibility model is important and values children's positive behaviors (...) this is key in this [intervention] program. (Reflexive journal, November)

\section{Recommended practices}

This subtheme highlights the objectives, strategies and activities deemed relevant for the TPSR intervention. Based on participant observations, it was considered important to develop explicit objectives towards respect for others, and create activities and use strategies that may help promote level I:

I started to observe at a distance the behaviors of these two [two children that were aggressive towards each other] and stopped it [a fight] right away and asked what was happening (...) For these cases it would be important to guide children towards the "peace bench» to solve their conflicts. (Reflexive journal, November) 
The 'peace bench' was a specific place in the gym that included two seats created by the program leader and enabled peaceful conflict resolution with the help of the program leader. The conversations in the peace bench always ended with a hug. Additionally, the program leader mentioned how strategies focused on fostering respect for others should be used: 'The moments in which there was a physically and psychologically unsafe climate show the great need and emergency of adopting responsibility-based strategies with this group of children, specifically strategies that serve as motivation to respect others' (Reflective journal, November).

\section{Intervention}

\section{Respect for the rights and feelings of others}

This subtheme focuses on the challenges faced by the program leader, responsibility-based strategies used and outcomes attained.

Challenges. The main challenge experienced by the program leader was guiding children through their emergent relational problems and difficulties in managing their emotions. It was possible to understand this challenge through an audio and video recording that captured teacher-student interactions: 'Have you decided the game? I do not want to (crying). Perhaps we could mix both games, right? Look, when you are sharing things we have to give away something and compromise'. In addition, in one of the sessions a child walked out of the activity and did not want to take part as assuring all children were able to control their emotions was also a challenge while implementing the TPSR model:

[In this activity] I had to repeat at lot of times that it is necessary to respect others and their ideas. They could only present a game they had decided to play as a group (...) I guided them to speak more (...) and reach a consensus. (Reflective journal, November)

Responsibility-based strategies and outcomes. A scoring system was also used to assess positive behaviours and to progress from an extrinsically motivating climate to an intrinsically one: 'On a daily basis, points were given to children (...) every day the program leader registered the points awarded to each child and at the end of the day there was a group meeting' (Reflexive journal, December, [second author's comments]) and 'While awarding points there were also significant discrepancies between points given [to each children] (...) in these cases there was always a discussion between children to reach a consensus' (Reflexive journal, December). Considering these challenges and the developmental stage of these preschool children, objectives associated with level I were shared using examples and concrete language to facilitate understanding as a formal set of 'levels' or long explanations about them were not effective: '... you have to choose a game without fighting (...) If you are able to choose a game without conflicts 15 points will be awarded' (Reflexive journal, November).

Individual conversations also played an important role:

... before awarding points I had an individual conversation with a girl who refused to play

(...) this child understood and admitted it was fair [getting fewer points than her classmates] and was willing to change her attitudes in other activities. (Reflexive journal, November) 
Teacher-student interactions reflected children's awareness about the need to respect others. This was clear while children were trying to a reach an agreement about a game to play and a set of rules that should be utilised: 'What rules have you created? Children replied - "First, you cannot push other people. You cannot grab someone also! You cannot fight and speak very loud" (...) We could mix both games'. The program leader added, 'He said a game and you said another one so combining games would be good'. A clear set of rules and the systematic use of activities focused on respect for others generated positive outcomes. Most children were able to solve conflicts if they emerged and communicate appropriately, however more responsibility-based strategies were deemed necessary:

Despite the fact that children were able to respect their colleagues in this activity, this was not always the case. There is much work to be done (...) however, there are children close to 'participation and effort' which should be developed in future activities. (Reflexive journal, November)

\section{Participation and effort, and self-direction}

This subtheme included the need to foster participation, effort, and self-direction, and included the challenges faced and strategies used by the program leader.

Children's developmental needs. At this stage of the TPSR intervention, children were able to present behaviours coherent with level I (respect for others). As such, activities started to focus on promoting effort (level II) and self-direction (level III): 'Today children were able to choose the game they would like to play. In this game they had the opportunity to create several figures (e.g. make a square) with their bodies in groups' (Reflexive journal, December).

Challenges. It was challenging to address children's developmental needs because they responded quite differently and were included in different levels of responsibility:

Most children (...) did not think about the rest of the group and they had to help each other (...) this child is much more advanced in the responsibility levels in comparison with rest of the group (...) two children were also follow [this type of responsibility behaviors]. (Reflexive journal, December)

At this stage of the intervention, children were in different levels of responsibility (level II and III) which lead to a reflection on what responsibility-based strategies could be used to set expectations and value behaviours considering each child's needs.

Responsibility-based strategies and outcomes. Based on these developmental needs and challenges, children were provided with choices as there was the need to be concrete to guide these discussions:

In each of the games I gave them freedom to choose which child would be the first to play (...) they all placed their arms up and said 'Me'. In these cases, I told them that had to choose which colleague would start and respect opinions without arguing. One boy quickly turned to the others and said 'Do you all agree that I can start?'. (Reflexive journal, January) 
Interactions between the program leader and children also reflected the efforts made to foster self-direction:

In this game, you will choose what to do. These cones are bowling cones. Do you know bowling? You will choose how to play it. A child replied - 'I know, you have to grab and throw'. Very well (...) as a group you will choose how to place them [the cones]. (Reflexive journal, January)

The aforementioned responsibility-based strategies were still being implemented at this stage.

\section{Caring}

This subtheme included children's developmental needs at this stage of the intervention, as well as strategies used and outcomes attained.

Children's developmental needs. Moving towards the end of the intervention period, most children were able to progress to level IV of Hellison's model: 'Groups were created based on (...) those who were more developed in communicating and helping others' (Reflexive journal, January) and 'At this stage tasks are designed to enable children to help each other by including children who interact few times with each other' (Reflexive journal, November, [second author comments]).

Responsibility-based strategies and outcomes. Activities were designed to motivate children to help each other in order to finish a specific set of motor tasks: 'We have created several stations that include motor challenges. Children are paired in groups as all the members of a team have to complete the challenge to advance to the next one' (Reflexive journal, December) and 'Two children are blindfolded and another has her mouth covered (...) two children do not have any limitations and have to help the others overcome a series of motor tasks' (Reflexive journal, December). At this stage, children served as role models and peer leaders as these tasks were explicitly presented to them:

It was important for them to feel what others felt and realize we do need to help others without them asking us to do it (...) Some children left me surprised by helping others even the ones who were blindfolded. (Reflexive journal, December)

Teacher-student interactions reflected children's focus on helping others: 'Have all of you finished the challenge? "I have not". So, if one of us cannot overcome something what should we do? "Help! OK, we will help you. Come!” (Reflexive journal, December). By the end of the intervention, children only reached level IV as transfer was not developed explicitly.

\section{Future recommendations}

\section{Need for a long-term TPSR intervention}

This subtheme included the program leader's reflections on the need to develop a longterm TPSR intervention to generate more outcomes. By the end of the intervention, it was clear the need to prolong the program to further develop transfer to other life domains as most children only reached level IV: 'These three months of implementation 
showed it was possible to foster positive outcomes through rewards and valuing positive behaviors (...) there is the need to continue the program to promote responsibility more effectively' (Reflexive journal, January) and 'These programs are implemented through a longer period of time (...) this was a start for behavioural change and should be continued' (Reflexive journal, January). In fact, TPSR is still novel in the Portuguese context and its application in a preschool context needs to be further developed: Future initiatives should create solid grounds for intervention programs to persist over time and overcome the limits of a research study: 'It is necessary to understand the strategies but beyond that the TPSR philosophy. It is complex, takes time, a lot of hours reading, discussing, and doing it, but these children need it now and tomorrow' (Reflexive journal, January, [second author's comments]).

\section{Discussion}

This action-research study aimed to understand the experiences of a program leader who is new to the TPSR model while implementing a TPSR-based program within a preschool setting. In the present study, action-research enabled the researchers to understand children's responsibility behaviours and create a TPSR intervention that was followed by multiples action-research cycles that reflected children's needs, challenges faced by the program leader, strategies used and outcomes attained. Researchers could consider developing a similar methodological design to further analyse how an TPSR-based intervention may be designed to fit a specific context and monitor progress in children's and teacher's responsibility behaviours over time (Escartí et al., 2012). Based on the observational data, it was clear there was not any intentionally designed intervention program in place to facilitate responsibility outcomes. In certain cases, teachers and other adult leaders who deliver these type of programs still focus on an unintentional approach towards these outcomes (Bean \& Forneris, 2016). Recent research has acknowledged that a life skills focus may generate more responsibility outcomes and enable social and emotional learning (Wright \& Stork, 2013). Teacher education programs and universities could introduce the TPSR model for teachers to promote personal and social skills. Future research could analyse how a TPSR-focused teacher education program may influence teacher's and student's responsibility behaviours in comparison to a traditional teacher education program that uses an unintentional approach.

This study provides a novel contribution to the TPSR literature and highlights the type of adaptations needed to implement a TPSR-based program in a preschool context. One of the adaptations included the use of effective communication skills were key to convey expectations and share responsibility behaviours associated to each level of the model. There was the need to use concrete language, visual references (e.g. pyramid) and examples to define TPSR objectives and focus preschool children on desired behaviours. An illustrated pyramid that included expressions and typical positive behaviours and attitudes was used to share responsibility goals. In fact, several studies have mentioned the importance of mastering effective communication skills while fostering responsibility outcomes as teachers should consider model implementation as a context-specific endeavour (Martinek, Schilling, \& Hellison, 2006; Weiss, Stuntz, Bhalla, Bolter, \& Price, 2013). Selfreport strategies and visuals like the ones mentioned in this study, presented the levels of responsibility in a concrete way. This appeared to be a responsive and developmentally 
appropriate way to help younger children understand and reflect on this material. This insight may be helpful for educators implementing a TPSR program with younger children who need a specific set of cues, information and guidance to promote school readiness with preschool children. This program also focused on reinforcing positive behaviours associated to each level of responsibility. Another adaptation was that if children presented positive responsibility behaviours medals and points would be given. This was a common strategy used to facilitate all the responsibility levels developed throughout the intervention and was considered useful to help change children's behaviours. This strategy was used as a tool for learning, focused only on positive behaviours, and consisted of an instructional aide appropriate to children's cognitive, emotional and social developmental stage. The TPSR model is based on the premise of creating an intrinsically motivating environment, which apparently might not be aligned with this strategy. However, considering the developmental needs of this age group and the challenges faced by the program leader this might be a relevant responsibility-based strategy as teachers should promote a transition between an extrinsically motivated environment to an intrinsically one (Deci \& Ryan, 2008; Seligman \& Csikszentmihályi, 2000). A different approach has been used in other TPSR-based programs as most interventions have been conducted with adolescent youth that may have specific developmental needs (Barker \& Forneris, 2012). Additionally, the different levels of responsibility were developed progressively and by the end of the intervention it was not possible to promote transfer (i.e. level V) as most children only reached level IV. Several researchers (Escartí et al., 2012; Hellison, 2011) have acknowledged the need to develop a less rigid understanding of the TPSR model and the need to develop all levels of responsibility. However, based on the children's developmental needs and the school's philosophy and curriculum, it was deemed more appropriate to implement a step by step approach which was one of the intentional adaptations made to fit the context which has been used in previous research (Jung \& Wright, 2012).

Based on the emergent challenges while delivering the TPSR model, the program leader took advantage of teachable moments and intentionally structured activities to promote respect, effort, self-direction and leadership which has been reported in previous research (Jung \& Wright, 2012; Pritchard \& Nieuwerburgh, 2016). In order to facilitate these responsibility levels, activities were designed to focus on motor skills and responsibility behaviours as children were provided with appropriate opportunities to solve relational issues, that promoted engagement, had the possibility to make decisions, voice their opinions and help others. The creation of the 'peace bench' and individual conversations helped the program leader overcome children's challenging behaviours and promote respect. This approach had a positive influence contrasting with the deficit-based approach that was used prior to the intervention. TSPR-based programs have included similar strategies with promising results and have showed to be effective in facilitating responsibility outcomes (Hemphill et al., 2015; Li, Wright, Rukavina, \& Pickering, 2008). The need of choosing appropriate activities and engage children was critical to facilitate effort as several studies have reported the importance of developing fun and enjoyment and explicitly focusing on effort as a relevant life skill (Weiss et al., 2013). On the other hand, curriculum ownership was deemed useful to provide voices and choices to the participants in the program. In certain cases, there is a general notion this may be a complex endeavour to accomplish in a preschool context. In the present study, the program leader provided opportunities for children to make decisions 
appropriate to their cognitive level and overall developmental stage which may differ in complexity from most TPSR interventions (Hellison, 2011). Additionally, students also had opportunities to fulfil leadership roles and were given opportunities to help others and serve as positive peer role models. The importance of creating solid grounds for leadership development has been mentioned in previous research as programs should be designed to provide all children with these type of opportunities (Martinek et al., 2006; Martinek \& Hellison, 2009). Future research could further understand how preschool children's responsibility behaviours may change from a TPSR-based intervention throughout a complete school year. Additionally, given the interdisciplinary nature of the curriculum in preschool contexts the TPSR model may be embedded in other areas and domains. Observational instruments such as the TARE (Wright \& Craig, 2011) could also be utilised to assess model fidelity more systematically and further assess program implementation.

Finally, while implementing a TPSR-based program there is the need to focus on each child's needs, interests and use a differentiated pedagogical approach. In this case, the program leader struggled in creating a set of differentiated responsibility goals based on participants' divergent developmental paths. To overcome this challenge, children were exposed to different activities that focused on specific responsibility levels. This feature should be considered in PYD and TPSR-based programs targeting life skills development as children could respond differently throughout an extended period of time (Hellison, 2011; Martinek \& Hellison, 2009). On the other hand, while intervening in 'real life' contexts it is necessary to provide solid grounds for program sustainability over time. In this case, the program leader was assisted by a researcher familiar with the TPSR model who served as a critical friend. It is advisable to develop interventions programs in which trained program leaders may develop interventions with other educational agents who can support the program's sustainability over time (Wright, Jacobs, Ressler, \& Jung, 2016).

\section{Conclusions}

This study provided a novel understanding of how TPSR may be implemented in a preschool context to foster social and emotional learning and enhance school readiness. It was clear several adaptations were needed to integrate aspects of the TPSR model as the program leader created a set of context-specific responsibility strategies that may provide insight for other educational agents to intervene in preschool contexts. The present study also highlighted how the TPSR model may be developed with preschool children and should be considered a relevant framework to attain positive developmental outcomes. More research is needed while integrating the TPSR model in preschool contexts.

\section{Disclosure statement}

No potential conflict of interest was reported by the authors.

\section{Notes on contributor}

Inês Pavão was a master's student at the School of Higher Education in Viana do Castelo and her interests lie in facilitating positive developmental experiences for preschool children and enhancing 
our understanding on to implement the TPSR model in this setting. Fernando Santos is a lecturer at both the Polytechnic Institute of Porto, Higher School of Education and the Polytechnic Institute of Viana do Castelo in Portugal. His main areas of research interest include positive youth development through physical education. He currently works on a research project examining how the TPSR model may be implemented within preschool education. Paul M. Wright is a professor at the Northern Illinois University and his interests lie in the TPSR instructional model. His research relates directly to fields such as positive youth development, social and emotional learning, and sport for development. He is also interested in policy and program evaluation as it relates to youth and physical activity. Francisco Gonçalves is a lecturer and physical education teacher that has attempted to investigate how physical education may be conducive to a range of positive outcomes. He has conducted several research projects focused on program evaluation and implementation.

\section{References}

Barker, B., \& Forneris, T. (2012). Reflections on the implementation of TPSR programming with atrisk-youth in the city of Ottawa, Canada. Agora para la Educación Física y el Deporte, 14(1), 7893.

Bean, C., \& Forneris, T. (2016). Examining the importance of intentionally structuring the youth sport context to facilitate positive youth development. Journal of Applied Sport Psychology, 28(1), 410-425.

Casey, A. (2013). 'Seeing the trees not just the wood': Steps and not just journeys in teacher action research. Educational Action Research, 21(2), 147-163.

Damon, W. (2004). What is positive youth development? The Annals of the American Academy of Political and Social Science, 591, 13-24.

Danish, S., \& Nellen, V. (1997). New roles for sport psychologists: Teaching life skills through sport to at-risk youth. Quest, 49, 100-113.

Deci, E., \& Ryan, R. (2008). Self-determination theory: A macrotheory of human motivation, development, and health. Canadian Psychology/Psychologie canadienne, 49(3), 182-185.

Denzin, N., \& Lincoln, Y. (2011). The SAGE handbook of qualitative research (4th ed.). Los Angeles, CA: Sage.

Durlak, J., Weissberg, R., Dymnicki, A., Taylor, R., \& Schellinger, K. (2011). The impact of enhancing students' social and emotional learning: A meta-analysis of school-based universal interventions. Child Development, 82(1), 405-432.

Dusenbury, L., Zadrazil, J., Mart, A., \& Weissberg, R. P. (2011). State learning standards to advance social and emotional learning. Chicago, IL: CASEL - Collaborative for Academic, Social, and Emotional Learning.

Erikson, E. (1968). Identity, youth and crisis. New York: Norton.

Escartí, A., Pascual, C., Gutiérrez, M., Marín, D., Martínez, M., \& Tarín, S. (2012). Applying the teaching personal and social responsibility model (TPSR) in Spanish schools context: Lesson learned. Agora para la Educación Física y el Deporte, 14(2), 178-196.

Fereday, J., \& Muir-Cochrane, E. (2006). Demonstrating rigor using thematic analysis: A hybrid approach of inductive and deductive coding and theme development. International Journal of Qualitative Methods, 5(1), 80-92.

Fraser-Thomas, J., Côté, J., \& Deakin, J. (2005). Youth sport programs: An avenue to foster positive youth development. Physical Education and Sport Pedagogy, 10(1), 19-40.

Hamre, B., \& Pianta, R. (2005). Can instructional and emotional support in the first-grade classroom make a difference for children at risk of school failure? Child Development, 76, 949-967.

Hellison, D. (2011). Teaching personal and social responsibility through physical activity (3rd ed.). Champaign: Human Kinetics.

Hemphill, M., Templin, T., \& Wright, P. (2015). Implementation and outcomes of a responsibilitybased continuing professional development protocol in physical education. Sport, Education and Society, 20(3), 398-419. 
Heroman, C., Burts, D. C., Berke, K., \& Bickart, T. (2010). Teaching strategies GOLD objectives for development \& learning: Birth through kindergarten. Washington, DC: Teaching Strategies.

Holt, N. (2016). Positive youth development through sport (2rd ed.). London: Routledge.

Holt, N., Neely, K., Slater, L., Camiré, M., Côté, J., Fraser-Thomas, J., ... Tamminen, K. (2017). A grounded theory of positive youth development through sport based on results from a qualitative meta-study. International Review of Sport and Exercise Psychology, 10(1), 1-49.

Jacobs, J., \& Wright, P. (2014). Social and emotional learning policies and physical education. Strategies, 27, 42-44.

Jung, J., \& Wright, P. (2012). Application of Helisson's responsibility model in South Korea: A multiple case study of 'at-risk' middle school students in physical education. Agora para la Educación Física y el Deporte, 14(2), 140-160.

Lee, A. (2009). An action research on applying teaching personal and social responsibility model (TPSR) in elementary physical education. Korean Association of Sport Pedagogy, 16(4), 153-174.

Lerner, R., Wang, J., Chase, P., Gutierrez, A., Harris, E., Rubin, R., \& Yalin, C. (2014). Using relational developmental systems theory to link program goals, activities, and outcomes: The sample case of the 4-H study of positive youth development. New Directions for Youth Development, 144, 17-30.

Li, W., Wright, P. M., Rukavina, P. B., \& Pickering, M. (2008). Measuring student's perceptions of personal and social responsibility and the relationship to intrinsic motivation in urban physical education. Journal of Teaching in Physical Education, 27(2), 167-178.

Liu, M., Karp, G., \& Davis, D. (2010). Teaching learning-related social skills in kindergarten physical education. Journal of Physical Education, Recreation and Dance, 81(6), 38-44.

Martinek, T., \& Hellison, D. (2009). Youth leadership in sport and physical education. New York: Palgrave Macmillan.

Martinek, T., Schilling, T., \& Hellison, D. (2006). The development of compassionate and caring leadership among adolescents. Physical Education and Sport Pedagogy, 11(2), 141-157.

Mashburn, A., Pianta, R., Hamre, B., Downer, J., Barbarin, O., Bryant, D., \& Burchinal, M. (2008). Measures of classroom quality in prekindergarten and children's development of academic, language, and social skills. Child Development, 79(1), 732-749.

Moreno, A., Nagasawa, M., \& Schwartz, T. (2018). Social and emotional learning and early childhood education: Redundant terms? Contemporary Issues in Early Childhood.

Pica, R. (2006). Physical fitness and the early childhood curriculum. Young Children, 61, 12-19.

Pierce, S., Gould, D., \& Camiré, M. (2017). Definition and model of life skills transfer. International Review of Sport \& Exercise Psychology, 10(1), 186-211.

Pozo, P., Grao-Cruces, A., \& Pérez-Ordás, R. (2016). Teaching personal and social responsibility model-based programmes in physical education: A systematic review. European Physical Education Review, 22, 1-20.

Pritchard, M., \& Nieuwerburgh, C. (2016). The perceptual changes in life experience of at-risk adolescent girls following an integrated coaching and positive psychology intervention group programme: An interpretative phenomenological analysis. International Coaching Psychology Review, 11(1), 57-74.

Sanders, S. W. (2002). Active for life: Developmentally appropriate movement programs for young children. Washington, DC: National Association for the Education of Young Children.

Seligman, M., \& Csikszentmihályi, M. (2000). Positive psychology. An introduction. American Psychologist, 55, 5-14.

Severinsen, G. (2014). Teaching personal and social responsibility to juniors through physical education. Asia-Pacific Journal of Health, Sport and Physical Education, 5(1), 83-100.

Smith, B., \& McGannon, K. (2017). Developing rigor in qualitative research: Problems and opportunities within sport and exercise psychology. International Review of Sport and Exercise Psychology, 10(1), 1-21.

Sparkes, A., \& Smith, B. (2016). Qualitative research methods in sport, exercise and health: From process to product. New York: Routledge.

Walsh, D. (2008). Helping youth in underserved communities envision possible futures: An extension of the teaching personal and social responsibility model. Research Quarterly for Exercise \& Sport, 79(2), 209-221. 
Walsh, D., Ozaeta, J., \& Wright, P. (2010). Transference of responsibility model goals to the school environment: Exploring the impact of a coaching club program. Physical Education and Sport Pedagogy, 15(1), 15-28.

Ward, S., Parker, M., Henschel-Pellett, H., \& Perez, M. (2012). Forecasting the storm: Student perspectives throughout a teaching personal and social responsibility (TPSR)-based positive youth development program. Agora para la Educación Física y el Deporte, 14(2), 230-247.

Webster-Stratton, C., Reid, M., \& Hammond, M. (2004). Treating children with early-onset conduct problems: Intervention outcomes for parent, child, and teacher training. Journal of Clinical Child and Adolescent Psychology, 33(1), 105-124.

Weiss, M., Stuntz, C., Bhalla, J., Bolter, N., \& Price, M. (2013). 'More than a game': Impact of the first tee life skills programme on positive youth development: Project introduction and year 1 findings. Qualitative Research in Sport, Exercise and Health, 5(2), 214-244.

Wright, P., \& Craig, M. (2011). Tool for Assessing Responsibility-Based Education (TARE): Instrument development, content validity, and inter-rater reliability. Measurement in Physical Education and Exercise Science, 15(3), 204-219.

Wright, P., Jacobs, J., Ressler, J., \& Jung, J. (2016). Teaching for transformative educational experience in a sport for development program. Sport, Education and Society, 21(4), 531-548.

Wright, P., \& Li, W. (2009). Exploring the relevance of positive youth development in urban physical education. Physical Education and Sport Pedagogy, 14(3), 241-251.

Wright, P., \& Stork, S. (2013). Recommended practices for promoting physical activity in early childhood education settings. Journal of Physical Education, Recreation, and Dance, 84, 40-43.

Wright, P., White, K., \& Gaebler-Spira, D. (2004). Exploring the relevance of the personal and social responsibility model in adapted physical activity: A collective case study. Journal of Teaching in Physical Education, 23, 71-87. 